murmur in favour of the a.s rhythm. I was much interested in seeing this opinion, and turned to the paper in question, feeling quite sure that if the observation established anything definitely, it would be the early $v-s$ rhythm. I now beg to ask those readers of the JoU HNAL interested in the matter to look at the paper in Pfiiger's Archiv and say what they do tend to prove. I give the essential points here.

Weiss and Joachim have devised a most ingenious instrument called the phonoscope, by which they can record in a wonderful and unmistakable way the normal sounds of the heart and any murmurs louder than the very softest blowing type. They publish several tracings, of which two are appended, showing the murmurs of mitral stenosis. The points they make are:

1. The distance from the beginning of ventricular systole to the rise of the carotid pulse in a normal heart is 0.08 to 0.09 second.

2. In mitral regurgitation this is increased to from 0.125 to 0.15 second, according to the degree of muscle failure present. This fact appeared to the writers to be strange, but they explain it by suggesting that blood escapes back through the incompeten valve at the beginning of $v-s$ and delays the development valfe at $i-v$ egregure exactly what 1 say happens in the development of a crescendo murmur, causing delay of the first sound (see Fig. 2).

3. The crescendo murmur of mitral stenosis occurs well within 0.15 second of the carotid rise (Fig. 4). Time vibration 0.01 second.

4. Weiss and Joachim make a special note of the fact that if the time of commencement of contraction of the auricle before the rise in the carotid artery $(0.20$ second) be marked off on the tracings, no noticeable sudden alteration of the curve is seen there (Fig. 5). In Fig. 4 they point out that the first vibrations of the murmur are only 0.13-0.14 second removed from the carotid pulse.

Weiss and Joachim do not state what appears to be the obvious conclusion to their work, namely, that the crescendo murmur is $v-8$ rhythm, but I have written to them drawing their attention to this, and asking them to examine their records to see if they afford similar support to the early $v \&$ rhythm theory, an account of which I have sent them.

In my judgement these tracings are not proof positive that the auricle has nothing to do with the production of the crescendo murmur. As there is wanting on them a definite indjcation of the exact time of onset of $a \cdot 8$, it may be argued that the auricle contracts nearer to the carotid pulse in mitral stenosis than 0.20 second; but, on the other hand, one of the chief doctrines of the modern school of cardiology, advanced partly on the assumption of the synchronism of $a \cdot s$ and the crescendo murmur, is that the $a \cdot c$ interval (between the onset of $a-8$ and the carotid pulse) is often increased in mitral stenosis even to 0.40 second.

In conclusion I submit that I have shown that the $a$.8 rhythm of the crescendo murmur is not only highly disputable, but even entirely fallacious, and that the murmur is early $v . s$ in rhythm. It would be very instructive for all interested in the matter if Dr. Mackenzie will produce his "indisputable" evidence that the murmur is, in part or wholly, caused by $a-s$, so much of the super. structure of modern cardiology being founded on this belief. Then the two discordant views can be compared by readers of the JoURNAL.

BIBLIOGRAPHY.

Balfour, G. W. : Clinical Lectures on Diseases of the Heart, 1898, p. 118 .

Barclay, A. W. : Lancet 1872, vol,i, p. 283.

Brockbank, E. M.: (1) Med. Chron., June, 1897, November, 1901 ;

(2) Edin. Med. Journ., March and April, 1899, November, 1901

(3) The Murmurs of Mitral Disease, London, 1899 Dickinson, w. H.: (1) Lancet, 1887, vol. ii, p. 650; (2) ibid., 1899,
vol. ii, p. 799; (3) Occasional Papers on Medical Subjects, 1896, p. 225.

Galabin. A. L.: Guy's Hosp. Rep., 1875.

Hay. John: Graphic Methods in Heart Disease, 1909.

Keith, A. : (1) Journ. of Anat. and Physiol., vol. xlii, 1907 ; (2) Lancet, vol. $i, 1904$.

Lewis, Thomes: (1) Hill, Further Advances in Physiology, 1909. article, Pulse Records in their relation to the Events of the Human Cardiac Cycle: (2) Quar. Jou:"n. of Med., July, 1909.

.

Ormerod, i. I. : Med. Times and Gaz., 1864, vol. ii, p. 154

. Allbutt' 8 System of Medicine, 1898, vol. $v, 1014$.

2. 127

and Jorchim, G.: Archiv f. $d$ yes. Physiol. (Pflüger's) SCC, vol. cxxiii, p. 373.

\section{OBSERVATIONS CONCERNING THE BLOOD IN CHOREA AND RHEUMATISM.}

BY

CHARLES J. MACALISTER, M.D.EDIN., F.R.C.P.LOND, PHYSICIAN, ROYAL SOUTHERN HOSPITAI, LIVERPOOL, AND TO THE LIVERPOOL COUNTRY HOSPITAL FOR CHILDREN.

THE association which is generally supposed to exist between rheumatism and chorea is very difficult to under. stand, and I think we may fairly say that the question of their actual relationship is hardly settled yet. Rheumatism itself is a disease which has a much narrower interpretation to.day than it had some years ago, and a good many cases formerly classed as rheumatic fever are now known to belong to an entirely different category

In the Liverpool Royal Southern Hospital Reports for 1902 I referred to this fact, and directed attention to a series of cases which closely resembled rheumatic fever clinically, but were quite uninfluenced by treatment with the salicylates, and were found to result from toxic absorption from one or another of the mucous tracts. In chorea we have another disease which, although it frequently occurs in children who have suffered from antecedent rheumatic or rheumatoid conditions and is associated with endocardial and pericardial complications, cannot be said to be more than an ally of true rheumatism, and this supposed alliance rests only upon certain clinical similarities and effects which may possibly result from an entirely independent toxin.

It is upon this point that I have been endeavouring to gain some information recently by means of experiments with the bloods of the two diseases. I have also tried to discover whether any evidence can be found to prove or disprove that chorea is to be regarded as an infective disease. The infectivity of chorea is certainly suggested by the remarkable way in which it tends every now and then to become so prevalent as to appear to be epidemic. In November, 1907, there were 5 cases in the wards, all admitted within a few weeks. In 1908, of 18 indoor cases, May and October furnished more than half the admissions: and during May of this year I have had under my care no less than 8 cases, of which 4 presented themselves in one day. It has more than once happened in my experience that two children in the same family have developed the disease in succession, and on one occasion the return home of a convalescent child was followed by the admission of a sister with whom she slept. On making inquiries, I have sometimes found that two or more children in a school have had chorea in succession or simultaneously, and it seems possible that the old impression that children get. the disease by imitation may have arisen through the unsuspected infection of one patient from another.

H. C. Ross's method of telling whether leucocytes are living or dead ${ }^{1}$ by examining the blood on an agar film. containing atropin and a stain, has enabled us to investigate the effects of placing the leucocytes of healthy people. in the plasmata of patients suffering from various diseases. He has shown that if the leucocytes of one healthy person. are placed in the plasmata of other bealthy persons they live a somewhat shorter time than they do in their own plasma, whereas if they are placed in the plasmata of persons suffering from diseases which are due to or associated with certain toxins in the blood, their lives are greatly shortened. This fact has proved useful insomuch. that it has (so far as we can tell up to the present) placed in our hands a method of estimating to a considerable extent whether a disease of uncertain nature is accompanied by a toxin in the blood, and it was this generai principle which led to my suggesting that we might employ it to throw some light on the problem of the relationship between chorea and rheumatism.

I need not enter into all the details of the experiments, but shall very shortly explain their nature:

1. The first research had for its object the determination. of the presence or absence of a toxin in the blood of chorea patients. The chorea blood was mixed in a capillary tube with an equal volume of citrated solution, centrifugalized, and the corpuscles removed. To the remaining plasma a small volume of the blood of a healthy person was added. Simultaneously another tube was prepared by adding the same healthy person's corpascles to another healthy person's plasma. Both tubes were kept at $30^{\circ} \mathrm{C}$. and samples of the contained corpuscles were 
examined from time to time on the agar films. The numbers of living and dead corpuscles were counted and averages taken.

2. The same experiment and control were repeated with the blood of persons suffering from acute rheumatism.

3. The effect of placing chorea leucocytes in the plasmata of other patients suffering from chorea was tested against a control.

4. The result of adding rheumatic leucocytes to chorea plasma was observed.

The results of these experiments show (1) that there appears to be in the blood plasma of patients suffering from chorea a poison which is toxic to the leucocytes of healthy persons, and (2) that in the case of rheumatism the plasma does not appear to be so uniformly toxic; in fact, it seemed to bo hardly at all poisonous to healthy deucocytes.

Next comes the question, Does any immunity exist between the two diseases? If I place the corpuscles of a chorea patient in the plasma of another chorea patient, they will live nearly as long as the corpuscles of a healthy person's will live in anotber healthy person's plasma, showing that to some extent the blood cells have become immune to the toxin. This being so, if the toxin in acute rheumatism is similar to that in chorea, the same evidence of immunity should exist when the corpuscles of the rheu. matic patient are placed in the plasma of a patient suffering from chorea. When this experiment was carried out, however, it was found that their lives were invariably shortened, and one may infer from this that at all events some difference exists between the poisons in the two conditions.

H. C. Ross has recently made a very instructive experi ment showing the value of this method of estimating cellular immunity. I had in the Royal Southern Hospital some time ago a man who had been a morphinomaniac for years, and who habitually took large doses of the drug. His arms presented a mass of cicatrices caused by hypodermic punctures. It was found that his leucocytes lived longer in a citrated solution of morphine than a healthy man's leucocytes did in the same solution under exactly the same conditions, and the lasting properties of this immunity appear to be demonstrated by the fact that the leucocytes of another patient who had been addicted to morphine, but who stated that she had taken none for five months, still appeared to be more or less immune.

We have not been able to tell experimentally whether the immunity in chorea is similarly lasting, but clinically we know how apt the disease is to recur. We hope some time hence to repeat our observations on the bloods of the same patients to test this point. In all probability we shall find that immunity of a lasting character is manifest when the corpuscles of people who have scarlatina-or other infectious diseases which confer immunity-are placed in the plasmata of patients actually suffering from these diseases, whereas the same plasma will prove exceedingly poisonous to the corpuscles of those who are unprotected.

There is just one other point to note with reference to the blood conditions found in chorea and acute rheumatism. In the first two cases of chorea which were investigated there was a marked eosinophilia. The counts showed 20 per cent. of eosinophiles in one and 16 per cent. in the other. I thought this might possibly have been due to some unsuspected intestinal parasites, but examination of the stools for eggs, etc., gave absolutely negative results. Six or eight chorea bloods have been examined since then, and, with one exception, they have all presented this peculiarity. ${ }^{2}$ There has been no eosinophilia in any of the numerous cases of acute rheumatism we have examined, and we have here another important distinction between the two diseases. It is noteworthy that this eosinophilia was present in the blood of the child who developed the disease in hospital, and who has been already referred to as occupying a bed next to a chorea patient.

The abservations which I have made in my opinion rend to confirm the suspicion that there is less real association between chorea and rheumatism than is generally thought to be the case, and that chorea nay be due to an infective tox aemia of distinctive character.

$$
\text { REFERENCES. }
$$

1 Lancet, February 6th, 1903. 2 Eosinophilia in chorea has been previously recorded by Cabot. Clinical Examination of the Blood, 1904 Tournal, 1902, and Burr, Univ. Med. Mag., ix, p.'163.

\section{A CASE OF ENTEROSPASM SIMULATING ACUTE OBSTRUCTION.}

\begin{tabular}{|c|c|c|}
\hline $\begin{array}{l}\text { F. E. WYNNE, } \\
\text { M.B., } \\
\text { LEIGH, LANCS. }\end{array}$ & $\begin{array}{l}B Y \\
\text { and }\end{array}$ & $\begin{array}{c}\text { F. P. STURM, } \\
\text { CH.B., } \\
\text { LEIGH, LANCS. }\end{array}$ \\
\hline
\end{tabular}

Cases in which the existence of enterospasm has veen demonstrated during operation are still sufficiently rare to justify the publication of the following :

Mrs. G., aged 45, was seen by us in consultation on June 19th mas found to be suffering from symptoms which pointed to acute obstruction.

History.

Several similar attacks in the past had been diarnosed as biliary colic. Three vears previously acute obstruction had apparently supervened, but while arrangements were being made for immediate operation the bowels acted naturally and all symptoms subsided.

State on Examination.

When we saw her there had been no motion for four days, there was incessant vomiting, and intense pain which could be localized neither by the patient nor by palpation. The abdomen was distended and tympanitic, with some dullness in the righ iliac region. Abdominal respiration was present but impaired. The temperature was normal, the pulse 150. the facies typically abdominal. The diagnosis appeared to lie between obstruction from an impacted gall stone and appendicitis. The patient was in an extremely critical condition. Operation was offered and accepted.

The abdomen was operation. The abdomen was opened in the middle line between tine immediately crowded into the wound. These being protected by hot sterile cloths, a hand was introduced and a careful examination made of the abdominal cavity. The gall bladder was empty, the hernial orifices free, and the large intestine normal from the hepatic flexure to the rectum. The caecum was obscured by adhesions. Upon with drawing the examining hand a coil of collapsed and almost bloodless small intestine followed into the wound. Th distended jejunum traced downwards in search of a constricting band or other cause of obstruction. About $2 \mathrm{ft}$. beyond merged suddenly into the coil of colmerged suddenly into the coil of collapsed gut. There was no band nor any other constricting cause. The gut below the constricted coil was normal. The constriction was moving slowly but distinctly upwards-a fact that was confirmed by each of us and also by Mr. Pickup who was administering the anaesthetic. One of the distended coils was opened and evacuated. It was then found possible to return the intestines and examine the appendicular region.

an examine the appendicular regior An enlarged and congested appendix containin which proved ultimately to be all stone, was with difticulty dug out of the usual nest of adhesions deep in the pelvis. The the gall stone in a pouch of the swollen mucous membrave. Death.

The wound was closed and the patient put back to bed. She never rallied from the shock of the operation, in spite of intro venous transfusion of saline, but died at 8 o'clock the same evening.

The following points of interest emerge :

1. The association of old appendicular trouble with enterospasm suggests a reflex origin of this curious condition, and a possible explanation of certain cases of faecal vomiting, as the peristaltic action was reversed.

2. The history of repeated attacks of biliary colic is curious since only one gall stone was found, and that in the appendix. Many other gall stones must have succeeded in passing the trap.

3. A similar, though much less severe, attack three years previously had been relieved by a natural action of the bowels.

4. The case was a perfect clinical picture of acute at. dominal mischief, but without the abdominal rigidity usually associated with such conditions.

5. The unexpected collapse and death suggests that even a moderate amount of abdominal manipulation in these spastic conditions of the bowel involves an in ordinate degree of shock, a conclusion that is confirmed by the results of the majority of the other few cases of enterospasm that we have seen recorded. 